\title{
H19, a Marker of Developmental Transition, Is Reexpressed in Human Atherosclerotic Plaques and Is Regulated by the Insulin Family of Growth Factors in Cultured Rabbit Smooth Muscle Cells
}

\author{
David K.M. Han, ${ }^{\star}$ Zin Z. Khaing, ${ }^{\star}$ Robert A. Pollock, ${ }^{\ddagger}$ Christian C. Haudenschild, ${ }^{\S}$ and Gene Liau* \\ Departments of *Molecular Biology, ${ }^{\ddagger}$ Experimental Pathology, and ${ }^{\S}$ Virology, Jerome H. Holland Laboratory, American Red Cross, \\ Rockville, Maryland 20855
}

\begin{abstract}
H19 is a developmentally regulated gene with putative tumor suppressor activity, and loss of $\mathrm{H} 19$ expression may be involved in Wilms' tumorigenesis. In this report, we have performed in situ hybridization analysis of H19 expression during normal rabbit development and in human atherosclerotic plaques. We have also used cultured smooth muscle cells to identify $\mathrm{H} 19$ regulatory factors. Our data indicate that $\mathrm{H} 19$ expression in the developing skeletal and smooth muscles correlated with specific differentiation events in these tissues. Expression of H19 in the skeletal muscle correlated with nonproliferative, actin-positive muscle cells. In the prenatal blood vessel, H19 expression was both temporally and spatially regulated with initial loss of expression in the inner smooth muscle layers adjacent to the lumen. We also identified H19-positive cells within the adult atherosclerotic lesion and we suggest that these cells may recapitulate earlier developmental events. These results, along with the identification of the insulin family of growth factors as potent regulatory molecules for $\mathrm{H} 19$ expression, provide additional clues toward understanding the physiological regulation and function of H19. (J. Clin. Invest. 1996. 97:1276-1285.) Key words: developmental biology • skeletal muscle • smooth muscle • growth factors • atherosclerosis
\end{abstract}

\section{Introduction}

The H19 gene is developmentally regulated and exhibits tumor suppressor activity when introduced into cell lines derived from rhabdomyosarcomas $(1,2)$. Consistent with this tumor suppressor activity, a decrease in H19 expression is associated with the appearance of Wilms' tumor in the developing kidney (3). Additionally, the H19 gene is parentally imprinted, expressed only by the maternal allele $(4,5)$, and chromosomal abnormalities within the $11 \mathrm{p} 15.5$ region containing $\mathrm{H} 19$ are associated with the Beckwith-Wiedemann syndrome, a disease

Address correspondence to Dr. Gene Liau, Department of Molecular Biology, Jerome H. Holland Laboratory, 15601 Crabbs Branch Way, Rockville, MD 20855. Phone: 301-738-0658; FAX: 301-738-0465; E-mail: liau@usa.redcross.org David K.M. Han's current address is Department of Pathology, University of Washington, Seattle, WA 98195.

Received for publication 24 July 1995 and accepted in revised form 7 December 1995.

J. Clin. Invest.

(c) The American Society for Clinical Investigation, Inc.

0021-9738/96/03/1276/10 \$2.00

Volume 97, Number 5, March 1996, 1276-1285 characterized by numerous growth abnormalities and predisposition to childhood malignancies such as Wilms' tumor, adrenocortical carcinoma, hepatoblastoma, and rhabdomyosarcoma (6). Despite these findings, the function and the nature of the H19 gene product have remained obscure. Although this gene is transcribed by RNA polymerase II and exhibits classical properties of a translated mRNA such as RNA splicing and polyadenylation, it is not associated with polyribosomes in fetal mouse liver or in $\mathrm{C} 3 \mathrm{H} 10 \mathrm{~T} 1 / 2$ cells $(7,8)$. Furthermore, comparison between human, mouse, and rabbit $\mathrm{H} 19$ sequences revealed the lack of a conserved translational reading frame (7-9). These results, taken together, suggest that the bioactive $\mathrm{H} 19$ molecule is not a translated protein but may be the RNA itself. However, a formal possibility remains that some unusual mechanism is used to translate the H19 RNA $(10,11)$.

We have been studying blood vessel development in the rabbit and have focused on the late prenatal to early postnatal phase. During this period, vascular smooth muscle transition from an immature (high proliferative, high biosynthetic, and noncontractile) to a mature (low proliferative, low biosynthetic, and contractile) tissue $(12,13)$. To gain a better understanding of this process, we previously used differential screening to isolate cDNA clones that were expressed in fetal smooth muscle cells (SMCs) ${ }^{1}$ but not in adult cells (9). We identified a rabbit gene (F31) that was highly expressed in fetal smooth muscle and in cultured fetal SMCs but not in the adult, and this cDNA exhibited a $70 \%$ nucleotide sequence identity with human H19 (9). Subsequent studies revealed that F31 is most likely the rabbit homologue of the human H19 gene (14). In this work, we have used in situ hybridization to analyze the pattern of H19 expression during the late prenatal to early postnatal phase of rabbit development. Based on these and our previous findings, we also examined the possibility that H19 may be expressed in human atherosclerotic plaques. Finally, we have used cultured fetal SMCs to begin to identify factors that regulate the expression of the $\mathrm{H} 19$ gene.

\section{Methods}

Cell isolation. Fetal and newborn aortae were dissected and cleaned of fat and adventitia. The aortae were opened longitudinally and the endothelial layer was removed by gentle scraping with a razor. The tissues were subsequently cut into $2-\mathrm{mM}$ sections and incubated with an enzyme solution containing $0.4 \mathrm{mg} / \mathrm{ml}$ elastase, $1 \mathrm{mg} / \mathrm{ml}$ collagenase, and $1 \mathrm{mg} / \mathrm{ml}$ soybean trypsin inhibitor in Hanks' balanced salt solution. The mixture was incubated at $37^{\circ} \mathrm{C}$ for $20 \mathrm{~min}$, gently ti-

1. Abbreviations used in this paper: PCNA, proliferating cell nuclear antigen; SMC, smooth muscle cell. 
trated 30 times with a $10-\mathrm{ml}$ pipette to release the SMCs from the extracellular matrix, and subsequently filtered through a sterile steel mesh $(85 \mu \mathrm{m})$ to remove the undigested tissue. The enzymes in the solution containing the SMCs were neutralized by the addition of two volumes of media containing $10 \%$ FBS. The cells were subsequently harvested by centrifugation and seeded at $5 \times 10^{3} \mathrm{cells} / \mathrm{cm}^{2}$ in Medium 199 containing $10 \%$ FBS, $100 \mathrm{U} / \mathrm{ml}$ penicillin G sodium, $100 \mu \mathrm{g} /$ $\mathrm{ml}$ streptomycin sulfate, $0.25 \mu \mathrm{g} / \mathrm{ml}$ amphotericin $\mathrm{B}$, and $4 \mathrm{mM}$ L-glutamine. Cells were routinely passaged at a 1:5 ratio and used between passages four and five. For some experiments, SMCs were incubated in low serum media ( $0.5 \% \mathrm{FBS}, 10^{-6} \mathrm{M}$ insulin, and $5 \mu \mathrm{g} / \mathrm{ml}$ transferrin).

Tissue collection and preparation. Time-pregnant rabbits were killed and the fetuses were removed and used for isolation of SMCs or for histology. For in situ hybridization and immunohistochemistry the fetuses were perfused with $4 \%$ buffered formaldehyde for $15 \mathrm{~min}$, $70 \%$ ethanol for $15 \mathrm{~min}$, and stored in $70 \%$ ethanol overnight. The appropriate tissues were subsequently dissected out and embedded in paraffin by standard procedures. Human atherectomy specimens were flushed out of the instrument chamber with saline solution and fixed immediately with $4 \%$ buffered formaldehyde. After $1 \mathrm{~h}$, the specimens were immersed in $70 \%$ ethanol for storage and transportation. After dehydration, the tissue fragments were embedded in paraffin that allowed sectioning in the plane of their largest dimension (usually longitudinal). Routine stains included hematoxylin-eosin, trichrome-fibrin, and Van Gieson-elastin.

In situ hybridization. Paraffin-embedded sections of rabbit tis- sues and human atherectomy samples were dewaxed in xylene $\left(65^{\circ} \mathrm{C}\right)$ and treated with $1 \mathrm{mg} / \mathrm{ml}$ of proteinase $\mathrm{K}$ for $10 \mathrm{~min}$ at $37^{\circ} \mathrm{C}$. The rabbit tissues were hybridized with an antisense 35 mer oligonucleotide probe based on the sequence of F31 (5'-CTGTCCTCACCGTCACACCGGACCATGTCATGTCC-3') (9). This sequence is $97 \%$ identical between rabbit F31 and human H19. Human atherectomy specimens were hybridized with an antisense 44 mer oligonucleotide probe based on the sequence of the human H19 gene (5'CCACGTCCTGTAACCAAAAGTGACCGGGATGAATGCCTGGCTCC-3'). Oligonucleotide probes were labeled by tailing with ${ }^{35} \mathrm{~S}$-dATP using terminal deoxynucleotidyl transferase and hybridized to tissue sections as described with some modifications (15). For the rabbit samples the hybridization was carried out at $37^{\circ} \mathrm{C}$ and the wash temperature was increased to $41^{\circ} \mathrm{C}$. For the human atherectomy samples, hybridization was carried out at $50^{\circ} \mathrm{C}$ and the wash was carried out in $0.1 \times \mathrm{SSC}, 1 \mathrm{mM}$ DTT at $65^{\circ} \mathrm{C}$ for $1 \mathrm{~h}$. Control experiments using corresponding sense probes and known H19-positive tissues (placenta, fetal liver) and -negative tissues (brain) were also carried out to demonstrate the specificity of the hybridizations.

Northern analysis. Total cellular RNA was extracted from cultured fetal SMCs by guanidium isothiocyanate and cesium chloride ultracentrifugation as described previously (16). The purified RNA was size fractionated on a $1 \%$ formaldehyde agarose gel, transferred to nitrocellulose, and hybridized as described (16).

Immunocytochemistry. Serial paraffin-embedded sections of tissues $(5-\mu \mathrm{m}$-thick) were reacted for $1 \mathrm{~h}$ at room temperature with a monoclonal antibody that recognizes all the muscle isoforms of $\alpha$-actin
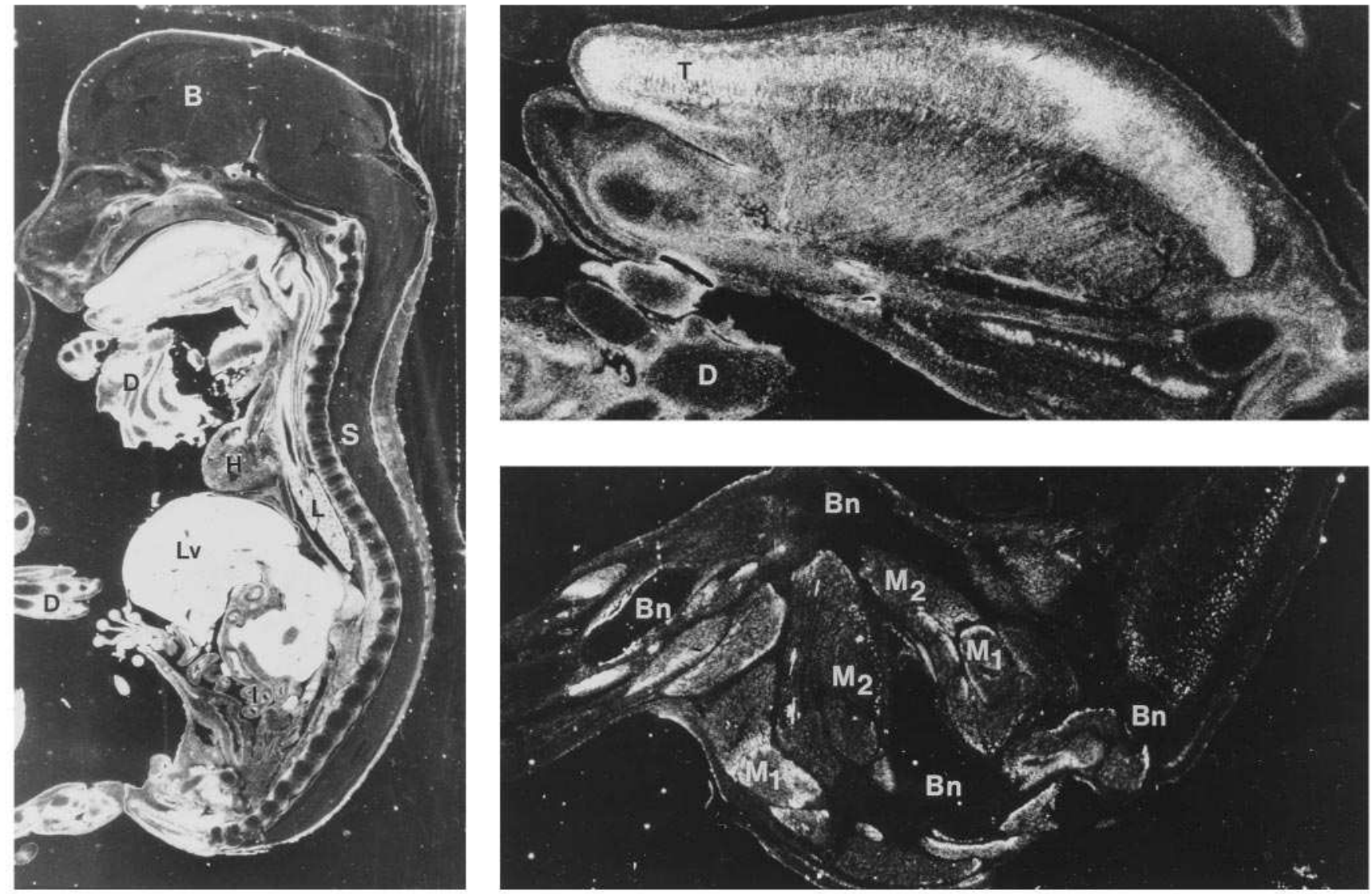

Figure 1. Expression of H19 RNA in the gestational day 20 rabbit fetus. In situ hybridization was performed as described in Methods, using a ${ }^{35}$ S-labeled 35-base oligonucleotide directed against rabbit H19 RNA. Sagittal section of a gestational day 20 fetus is shown under dark-field illumination. Higher magnification of the tongue and skeletal muscle of the thigh is shown on the top right and bottom right panels, respectively. $B$, brain; $H$, heart; $I$, intestine; $D$, digits of the forelimb; $L$, lung; $L v$, liver; $S$, spinal cord; $T$, tongue; $B n$, cartilaginous bone; $M_{l}$, muscle area containing a high level of $\mathrm{H} 19 ; M_{2}$, muscle area containing a lower level of H19. 
as well as $\gamma$-actin (diluted 1:50) (Dako Corp., Carpinteria, CA), and a monoclonal antibody that recognizes proliferating cell nuclear antigen (PCNA) (diluted 1:50) (Dako Corp.). Quantitation of the PCNApositive cells was carried out using a Zeiss light microscope, a CCD video camera, and Image-1 image analysis software. Aortic sections (three for each time point) were manually traced and total cells and PCNA-positive cells were counted. Primary antibodies were detected using biotin-conjugated secondary antibody and avidin horseradish peroxidase using a commercially available ABC kit (Vector Labs, Inc., Burlingame, CA). All antibodies were diluted in PBS containing $10 \%$ normal goat serum and $1 \%$ bovine serum albumin. Controls include omission of the primary antibody, nonimmune $\mathrm{IgG}$ of the same class, and known positive tissues: adult SMC of normal arterial media for actin, jejunum crypt epithelium for PCNA.

\section{Results}

H19 RNA expression is a marker of developmentally regulated differentiation in skeletal muscle. We performed in situ hybridization analysis to determine the overall prenatal tissue distribution of H19 RNA in a gestational day 20 rabbit fetus (rabbits have a gestational period of $30 \mathrm{~d}$ and the period between 20 and $30 \mathrm{~d}$ is roughly equivalent to $12.5-19 \mathrm{~d}$ in the mouse). Consistent with previous studies in the mouse and human (17, 18), H19 RNA was abundant in a variety of prenatal tissues including the liver, tongue, limb muscle, heart, kidney, and intestines (Fig. 1). By contrast, H19 was not expressed in neuroectodermal-derived tissues such as the brain and the spinal cord or in the ossification centers of the cartilaginous skeleton (Fig. 1). Since previous in vitro studies have suggested that H19 may function during muscle differentiation $(7,19)$, we analyzed the pattern of expression of this gene in greater detail in the devel- oping skeletal muscle. As shown in Fig. 1, we found that H19 expression in the tongue muscle of a 20 -d fetus exhibited a fibrillar pattern. Immunostaining of serial sections using antibodies directed against actin and PCNA revealed that a high level of H19 RNA colocalized with actin-positive muscle cells that generally lacked PCNA staining (Fig. 2). Additionally, we found that in the limb muscle $\mathrm{H} 19$ was also distributed in a distinctive pattern with particularly intense expression found in certain regions (M1) adjacent to the cartilaginous bone (Fig. 1). Similar to the tongue muscle, these areas of intense H19 expression were high in immunoreactive actin and lacked PCNA-positive cells (results not shown). Our results indicate that $\mathrm{H} 19$ expression in the developing skeletal muscle is not uniform but is positively correlated with differentiating cells high in immunoreactive actin and low in proliferative activity.

H19 expression is temporally and spatially regulated in the developing rabbit aorta. We next examined the expression of H19 RNA in the rabbit aorta during the period between gestational day 20 and 4 wk after birth. Since prenatal blood vessel development in the rabbit has not been examined in detail, we first characterized the prenatal developmental process with respect to morphology, actin and elastin expression, and cell proliferation. PCNA staining of the aorta from gestational days 20-29 neonatal and adult animals was performed to obtain a rough index of SMC replication rate (Fig. 3). At gestational day $20, \sim 65 \%$ of the cells were PCNA positive and the number of positive cells remained similar up to day 25. By gestational day 29 the PCNA-positive cells were reduced to $35 \%$ and only $10 \%$ of the cells were positive in newborn animals while 4-wk-old animals were negative. During this period a dramatic increase in the number and size of elastic fibers could
Actin

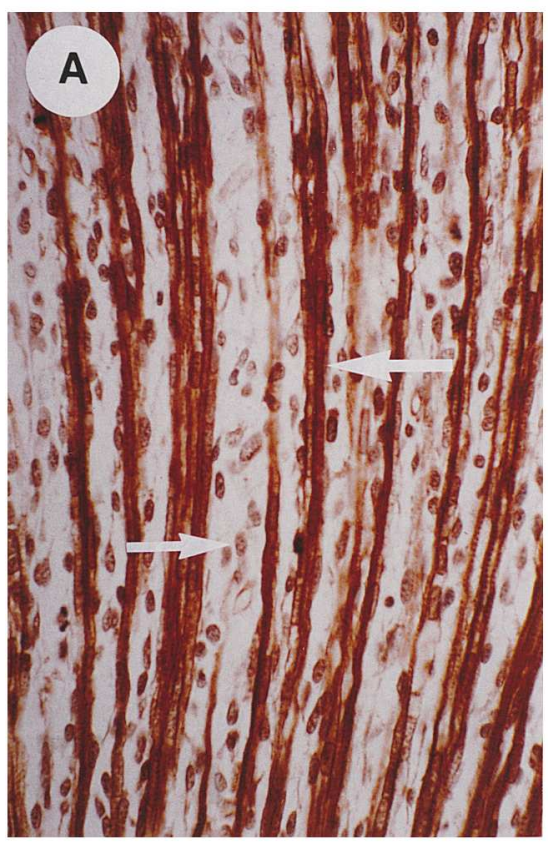

$H 19$

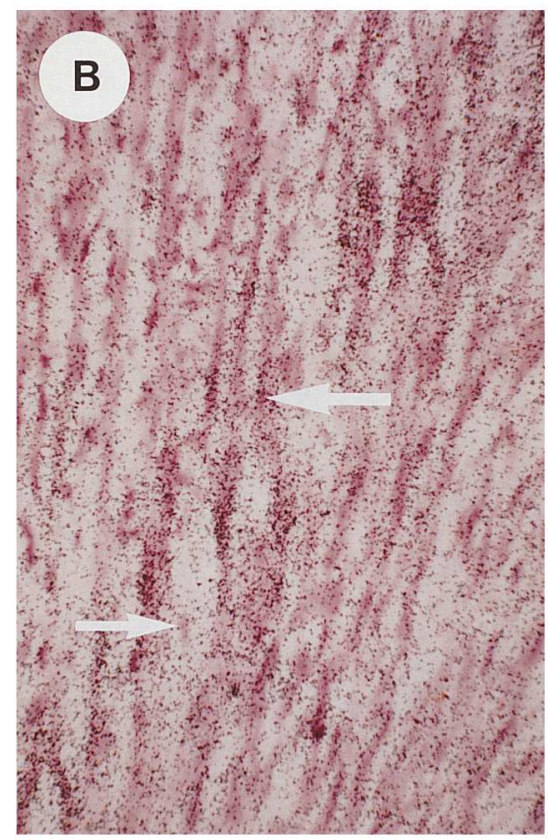

PCNA

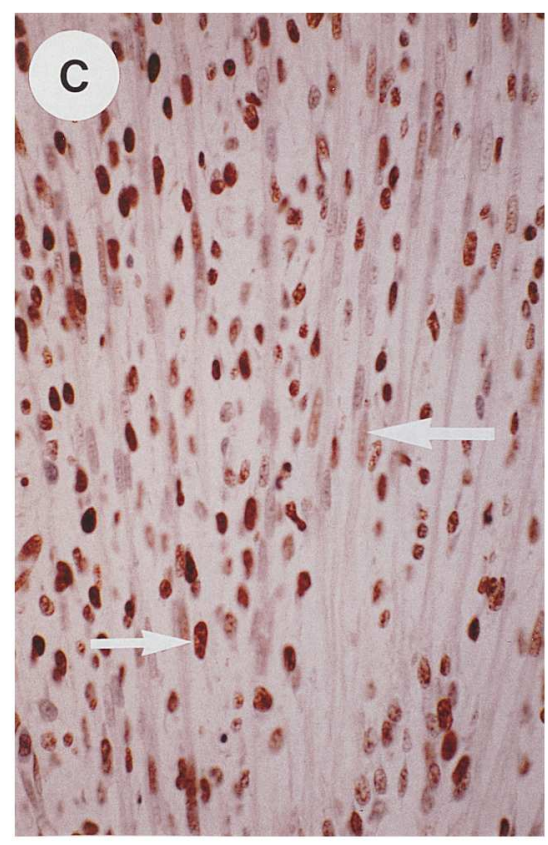

Figure 2. Expression of H19 RNA, actin, and proliferative state of muscle cells in the gestational day 20 rabbit tongue. A higher powered magnification of $\mathrm{H} 19$ expression in the tongue. Serial sections were also immunostained with actin and PCNA to demonstrate colocalization with actin-positive and PCNA-negative cells. Large arrows indicate actin-positive bundles $(A)$, H19-positive cells $(B)$, and PCNA-negative cells $(C)$. Small arrows indicate actin-negative cells $(A)$, H19-negative cells $(B)$, and PCNA-positive cells $(C)$. 
be observed (Fig. 3): at gestational day 20, only weakly stained, diffuse elastic fibers were present in the aorta. However, by gestational day 29, the elastic fiber content of the vessel wall greatly increased and became well organized (Fig. 3). Actin levels were not appreciably altered during this period. In situ hybridization revealed that in the gestational day 20 aorta, H19 was prominently expressed by the endothelial cells and also detectable in many of the SMCs (Fig. 4). However, the SMCs adjacent to the endothelium appeared to express a minimal level of H19, while the cells distal to the lumen contained a higher amount of H19 RNA. In the gestational day 25 aorta, prominent expression of H19 was maintained in the outer me- dial smooth muscle layers and in the adventitia while H19 expression in the endothelial monolayer and in the inner medial smooth muscle layers became minimal. In gestational day 29 and newborn animals, H19 expression in the aorta was modest and predominantly restricted to the adventitial cells while in the 4-wk-old animal, H19 RNA was not detected (Fig. 4). Our data indicate that $\mathrm{H} 19$ expression is both temporally and spatially regulated during rabbit blood vessel development.

H19 expression in cultured fetal SMCs is regulated by the insulin family of growth factors. As a first step toward understanding the complex pattern of H19 expression observed in vivo, we wish to identify factors that regulate the expression of

\section{0 days}
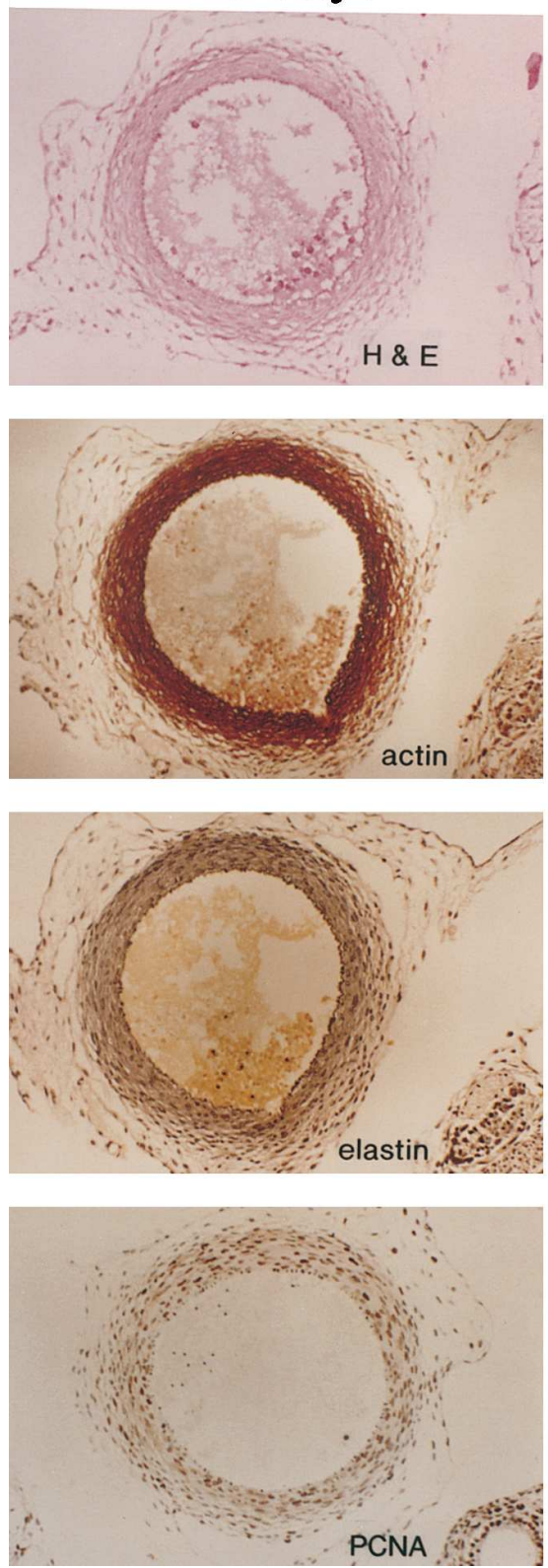

29 days
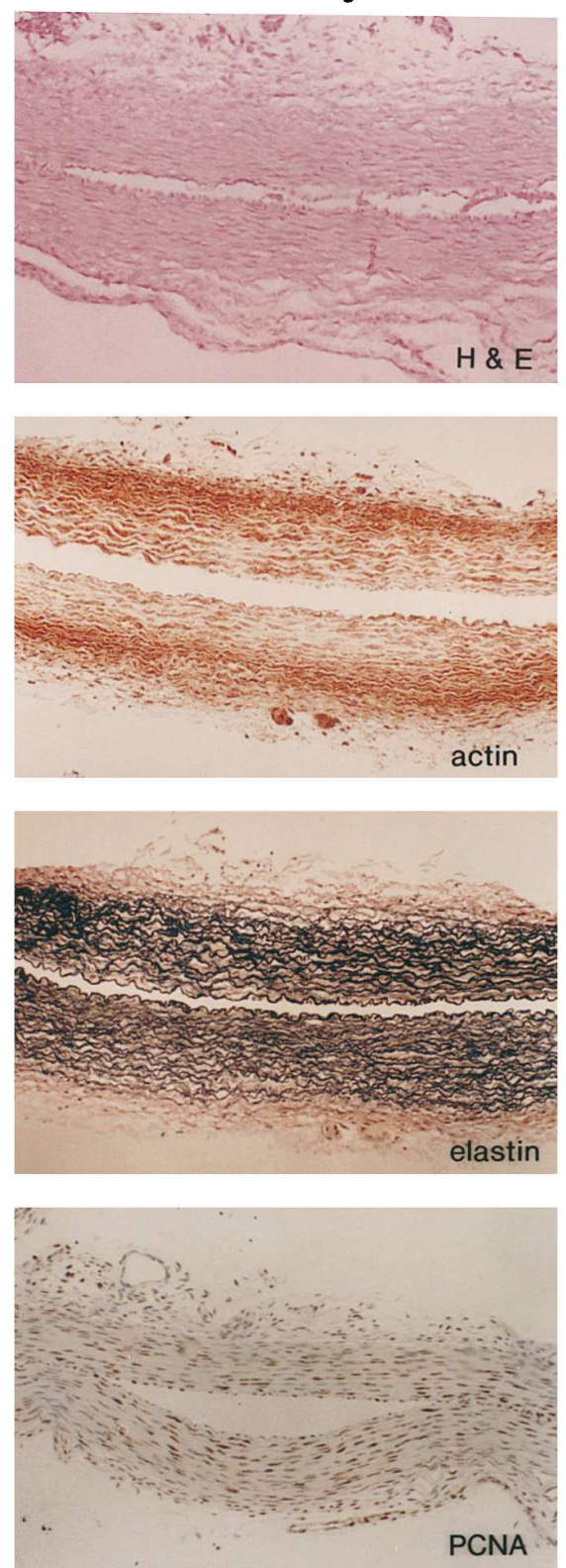

adult
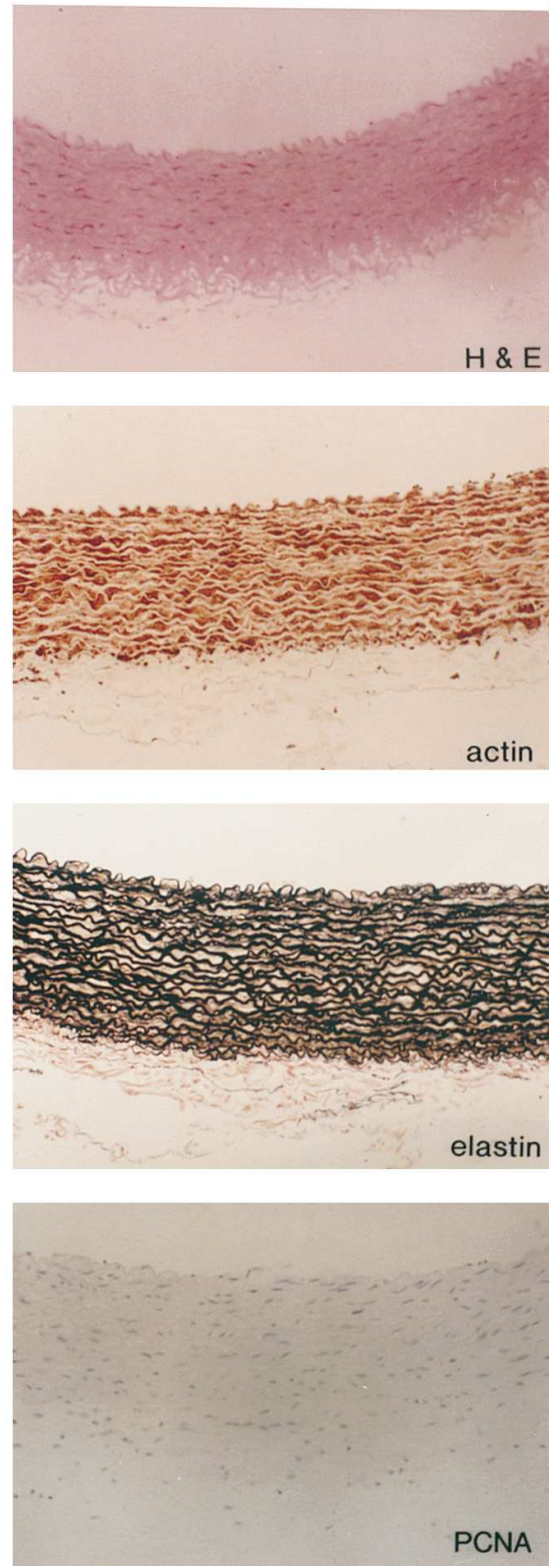

Figure 3. Characterization of rabbit thoracic aortae at gestational days 20 and 29 and in the adult animal. The aortic cross-sections were analyzed by hematoxylin-eosin staining, immunostaining with actin antibody (HHF35), Verhoeff's staining for elastic fibers, and PCNA immunostaining to determine the proliferative state of the cells. 
this gene. Cultured fetal SMCs were used for these studies since we have shown that developmental regulation of H19 is maintained in vitro with only the fetal cells capable of expressing H19 (9). Previously, it was found that H19 expression was abundant in preconfluent fetal SMCs but downregulated in confluent cells. However, confluent cells cultured in the presence of media containing $0.5 \%$ serum, $10^{-6} \mathrm{M}$ insulin, and 100 $\mu \mathrm{g} / \mathrm{ml}$ transferrin (low serum media) reexpressed H19 RNA (9). To gain a better understanding of the unexpected reexpression of $\mathrm{H} 19$ in the presence of low serum media, fetal
SMCs were cultured in media containing 10\% FBS until they became confluent and subsequently parallel dishes were cultured in normal media or in low serum media and analyzed for H19 RNA expression. As shown in Fig. 5 A, cells grown in the presence of normal media did not express H19 once they reached confluency. However, growth in low serum media permitted the reexpression of $\mathrm{H} 19$ by day 3 and enhanced H19 RNA level was maintained for at least $4 \mathrm{~d}$ (Fig. 5 B).

Several scenarios can be envisioned that explain the effect of low serum media on H19 RNA expression. One possibility
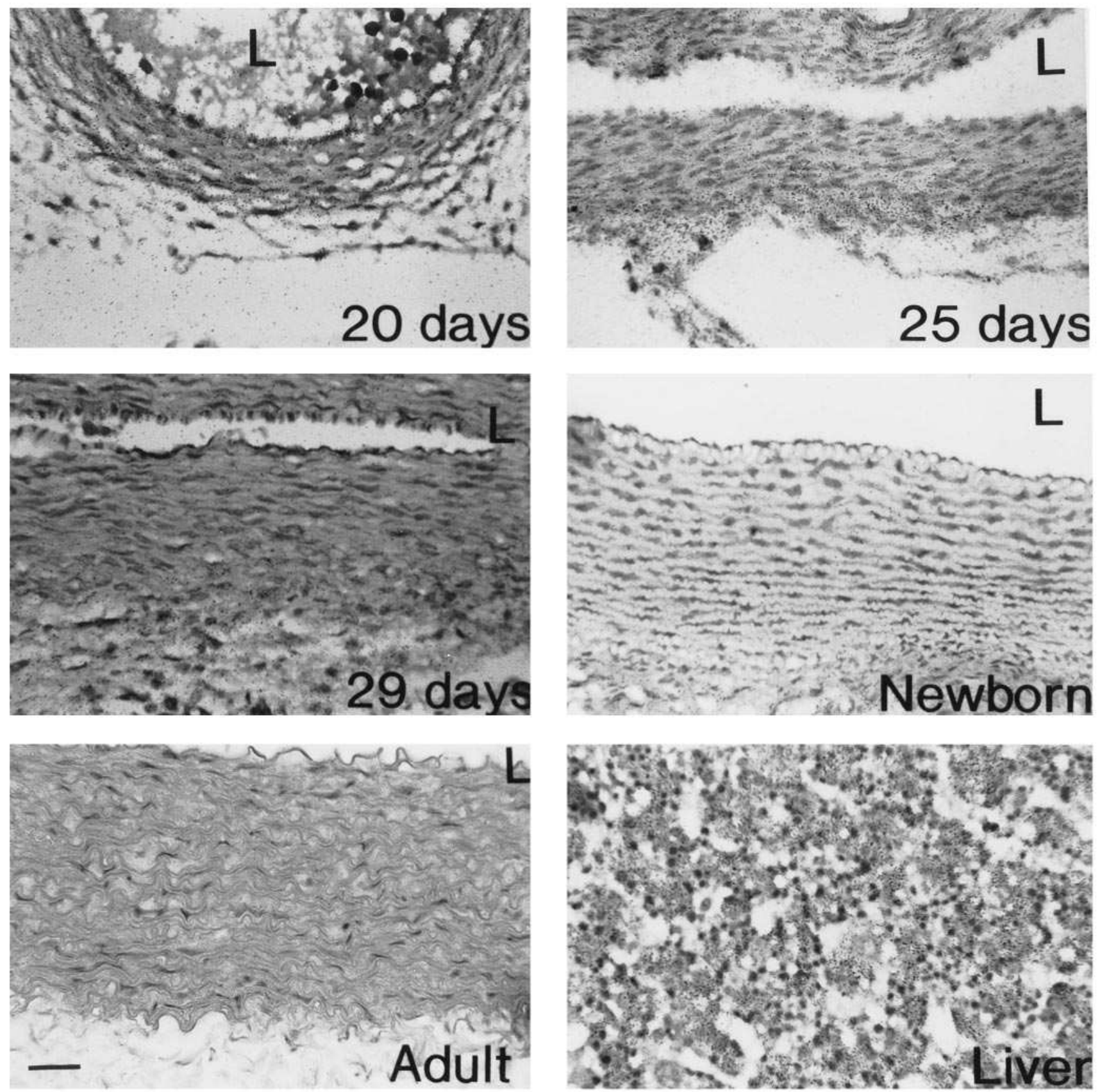

Figure 4. Analysis of H19 expression in the developing thoracic aorta. Thoracic aortae from gestational days 20, 25, and 29, newborn, and adult were analyzed for H19 RNA expression by in situ hybridization as described. Liver from a gestational day 20 animal expresses an abundant level of H19 RNA (Fig. 1) and is shown here as a positive control to provide a comparison with the amount of H19 expressed in the aortae. $L$, vessel lumen. Bar, $11 \mathrm{~mm}$. 
A

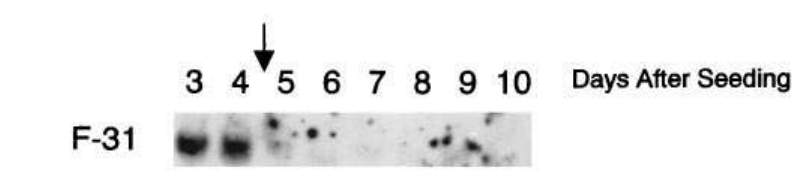

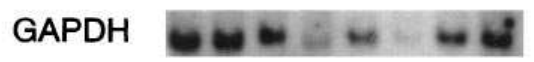

285

$18 S$

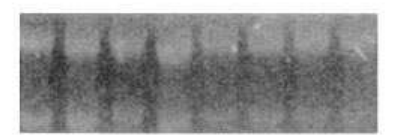

B

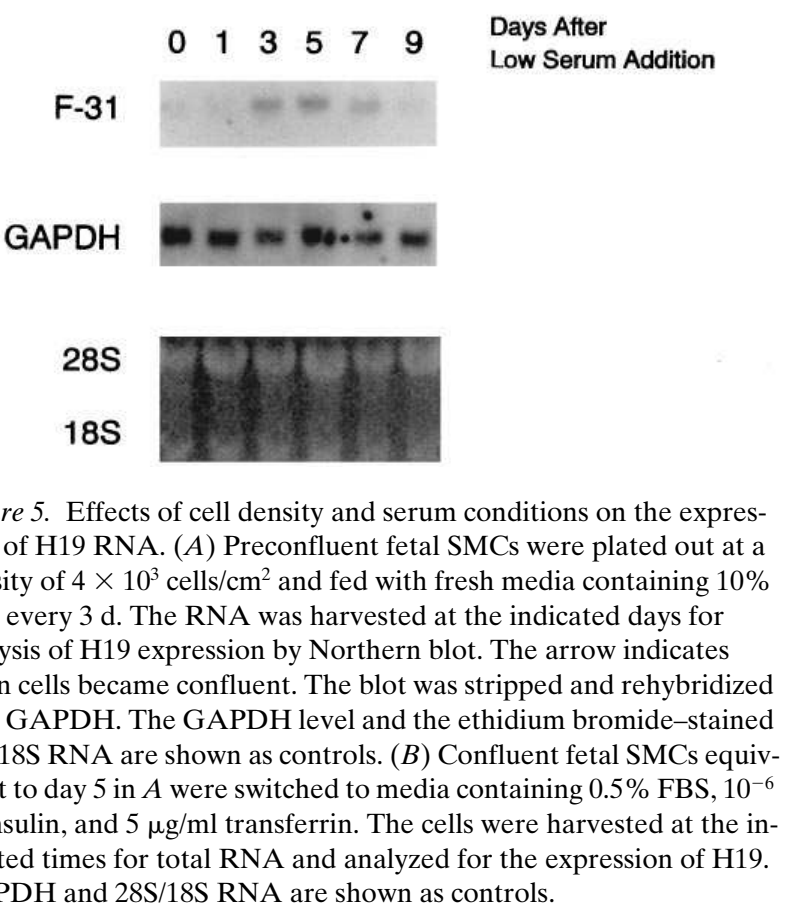

is that component(s) of low serum are responsible for the reexpression of H19. It is also conceivable that serum may contain or induce the synthesis of factors that negatively regulate $\mathrm{H} 19$ expression. We tested the first possibility by incubating confluent fetal SMCs with normal media, low serum media, or individual components of the low serum media for $3 \mathrm{~d}$ and subsequently analyzed H19 RNA levels (Fig. $6 A$ ). We found that cells cultured in the presence of insulin expressed the highest level of H19 RNA, approximately fivefold enhancement when compared with cells treated with media alone (Fig. $6 A$ ). This indicated that insulin was the major component of low serum media responsible for the enhanced expression of H19 RNA. Since the insulin family of growth factor also includes the structurally homologous IGF-I and IGF-II, we next tested the effect of these factors on $\mathrm{H} 19$ expression. As shown in Fig. $6 B$, cells treated with $10 \mathrm{ng} / \mathrm{ml}$ of IGF-I or IGF-II expressed a substantially higher level of H19 RNA than control cells. By contrast, cells treated with epidermal growth factor, fibroblast growth factor-1, or thrombin had a minimal effect on $\mathrm{H} 19$ ex-
A

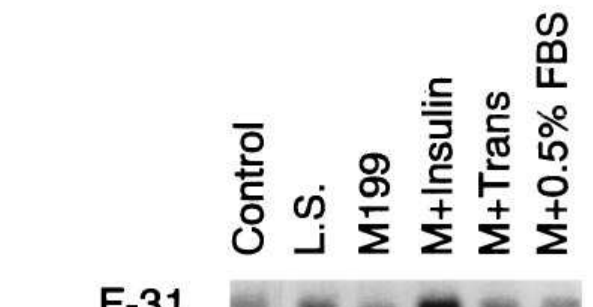

GAPDH $=-\infty+\infty$

285

$18 S$

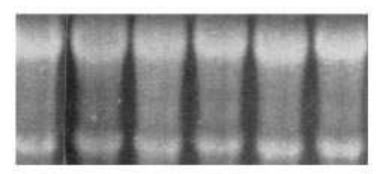

B
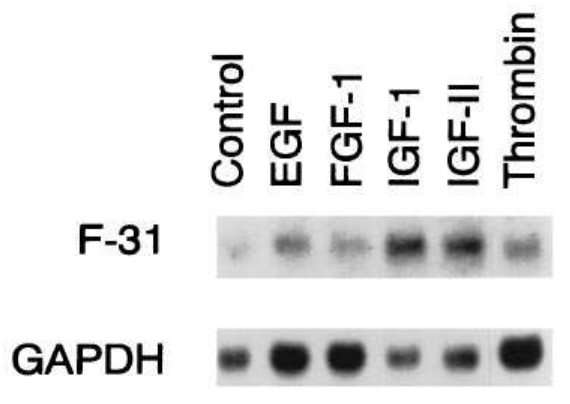

285

185

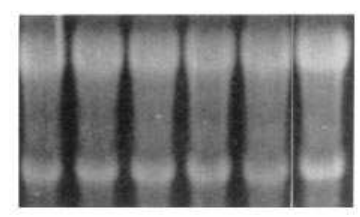

Figure 6. Regulation of $\mathrm{H} 19$ by components of low serum media and growth factors. $(A)$ Fetal SMCs were incubated for $3 \mathrm{~d}$ in low serum media or individual components of low serum media. RNA was prepared after $3 \mathrm{~d}$ of incubation and H19 expression was tested by Northern analysis. Control lane indicates the confluent fetal SMCs in $10 \%$ FBS containing media. L.S., low serum media; $M$, M199 medium; Trans, transferrin. GAPDH and 28S/18S RNA are shown as controls. (B) Fetal SMCs were incubated for $3 \mathrm{~d}$ in low serum media alone or together with $10 \mathrm{ng} / \mathrm{ml}$ of EGF, FGF-1, IGF-I, and IGF-II, and $1 \mathrm{U} / \mathrm{ml}$ of thrombin. The RNA was harvested and the expression of H19 was analyzed by Northern blotting.

pression. These results indicate that the insulin family of growth factors is a potent regulator of H19 RNA expression.

Next we tested the possibility that serum contains or induces the synthesis of factors that may inhibit the expression of H19. This possibility is consistent with the fact that the insulin family of growth factors is normally present in serum and, as shown in Fig. 6 A, insulin alone was considerably more effective in enhancing $\mathrm{H} 19$ expression than insulin in the presence 
of $0.5 \%$ serum. Cultured SMCs were incubated with low serum media for $2 \mathrm{~d}$ and subsequently with media containing $10 \%$ serum and analyzed for H19 expression. As shown in Fig. 7, expression of H19 was considerably enhanced in the presence of low serum media. However, replacement with media containing $10 \%$ serum resulted in a decline in H19 RNA expression by $10 \mathrm{~h}$ and by $36 \mathrm{~h}$, the level of H19 RNA was $\sim 10$ fold lower than low serum media-treated cells. These results indicate that serum contains or induces the synthesis of factors that inhibit the expression of H19 RNA.

H19 is expressed by intimal cells of the human atherosclerotic plaque. An important aspect of the human atherosclerotic plaque is the presence of modified SMCs that possess morphological and biochemical characteristics similar to developmentally immature SMCs (20-27). Since H19 RNA expression was developmentally regulated in the aortic smooth muscle and was not detected in normal adult smooth muscle (9), we performed in situ hybridization to test the possibility that cells in the atherosclerotic plaque could reexpress H19. As shown in Fig. $8 A$, H19 RNA was indeed abundantly expressed by some cells in the atherosclerotic plaque. The expression was not uniform, with cells expressing a very high level of H19 adjacent to H19-negative cells. We analyzed 10 human coronary atherectomy specimens and found that 7 of these contained a substantial number of H19-positive cells. To attempt to correlate H19 expression with morphological or biochemical features of atherosclerotic plaques, the H19-positive samples were further characterized with respect to collagen, elastin, and actin content as well as with respect to the proliferative state (PCNA) of the cells. Fig. 8, $A-D$, illustrates a typical area where a substantial number of H19-positive cells was found. Van Gieson staining revealed that this region contained a loose matrix that is characteristic of the "myxomatous" region of an atherosclerotic plaque (Fig. $8 \mathrm{~B}$ ). Myxomatous regions are generally enriched in stellate-shaped, actin-enriched cells with smooth muscle characteristics, and as shown in Fig. $8 \mathrm{C}$, most of the H19-positive cells stained intensely for muscle actin but were PCNA negative. The adjacent, relatively acellular region was highly enriched in dense fibrillar collagen (red) typical of a sclerotic region and was devoid of H19-positive cells. Shown in Fig. 8, $E$ and $F$, is a second intimal area containing a region (marked by the asterisk) that possessed elastic fibers

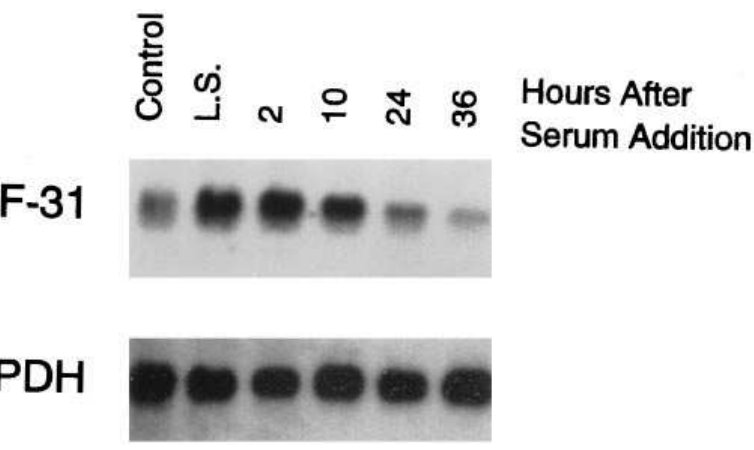

Figure 7. Serum regulation of H19 expression. Fetal SMCs were plated out at a low cell density $\left(4 \times 10^{3}\right.$ cells $\left./ \mathrm{cm}^{2}\right)$ and incubated in low serum media for $2 \mathrm{~d}$, media containing $10 \%$ FBS were added back to the cells, and RNA was isolated at indicated time points and tested for H19 expression by Northern analysis. GAPDH is shown as a control. (black) and spindle-shaped cells. These morphological features suggest that this is a segment of the coronary intima near the internal elastic lamina and represents the most mature and stable part of the intimal thickening. Although this region as well as the adjacent area composed of aligned cells and some thin elastic fibers contained mostly H19-negative cells, there were a few cells (an example is marked by open arrow) that did express H19. By contrast, the lumenal region, containing loose collagen fibrils but very little elastic fiber, had a number of randomly oriented, H19-positive cells (Fig. 8, $E$ and $F$ ). We conclude that a subpopulation of atherosclerotic plaque cells can reexpress $\mathrm{H} 19$ and some of these cells are likely intimal SMCs.

\section{Discussion}

H19 expression in skeletal muscle is consistent with a specific function during myoblast growth-arrest and differentiation. The function of H19 in skeletal muscle is of particular interest since it is one of the few tissues that continues to express detectable amounts of H19 RNA in the adult (28). Furthermore, $\mathrm{H} 19 / \mathrm{MyoH}$ is one of three genes isolated in a screen to identify myogenic determinant loci and cells transfected with MyoD express a high level of H19 only when they are capable of differentiating into myotubes (19). In this study, we demonstrated that H19 expression was not uniform in the developing tongue or limb muscle but was associated with growth-arrested cells committed to myotube formation. The pattern of expression in the tongue muscle is very similar to that reported for the cyclin-dependent kinase inhibitor, p21, a protein involved in cell cycle growth-arrest (29). Several studies have implicated p21 as a central player in the induction of cell cycle withdrawal before myogenic differentiation $(29,30)$. Does H19 also have a role in skeletal muscle cell growth-arrest and differentiation? Consistent with such a possibility is the finding that reintroduction of H19 RNA into rhabdomyosarcoma cell lines caused growth retardation and loss of tumorigenicity (2). Furthermore, enhanced H19 expression is associated with cellular growth-arrest and myogenic differentiation in the embryonic cell line C310T1/2s (19). Our in vivo finding that H19 expression is associated with prenatal skeletal muscle differentiation supports a specific function for H19 during myoblast growtharrest and differentiation.

H19 expression and smooth muscle maturation in the developing aorta. H19 was expressed by all cells of the 20-d prenatal blood vessel. However, with increased gestational age, H19 expression became restricted to the outer layers of vessel wall SMCs and to interstitial cells. H19 expression did not correlate with cell proliferation since PCNA-positive cells were evenly distributed throughout the medial layer. However, previous studies in the rat and the mouse have established that the inner smooth muscle layers of the developing blood vessel are the first to undergo elastogenesis and to acquire a mature, contractile phenotype and that this process did not correlate with cell proliferation $(12,31,32)$. Furthermore, smooth muscle myosin heavy chain, a highly specific marker for the SMC lineage (33), was detected first in the inner smooth muscle layers of gestational day 19 rabbit aorta (34). These results indicate that loss of H19 expression may be temporally and spatially correlated with acquisition of the mature SMC phenotype during prenatal development. Our data support a function for H19 during the transition to a mature smooth muscle with loss of H19 expression occurring after the initiation of smooth muscle myo- 

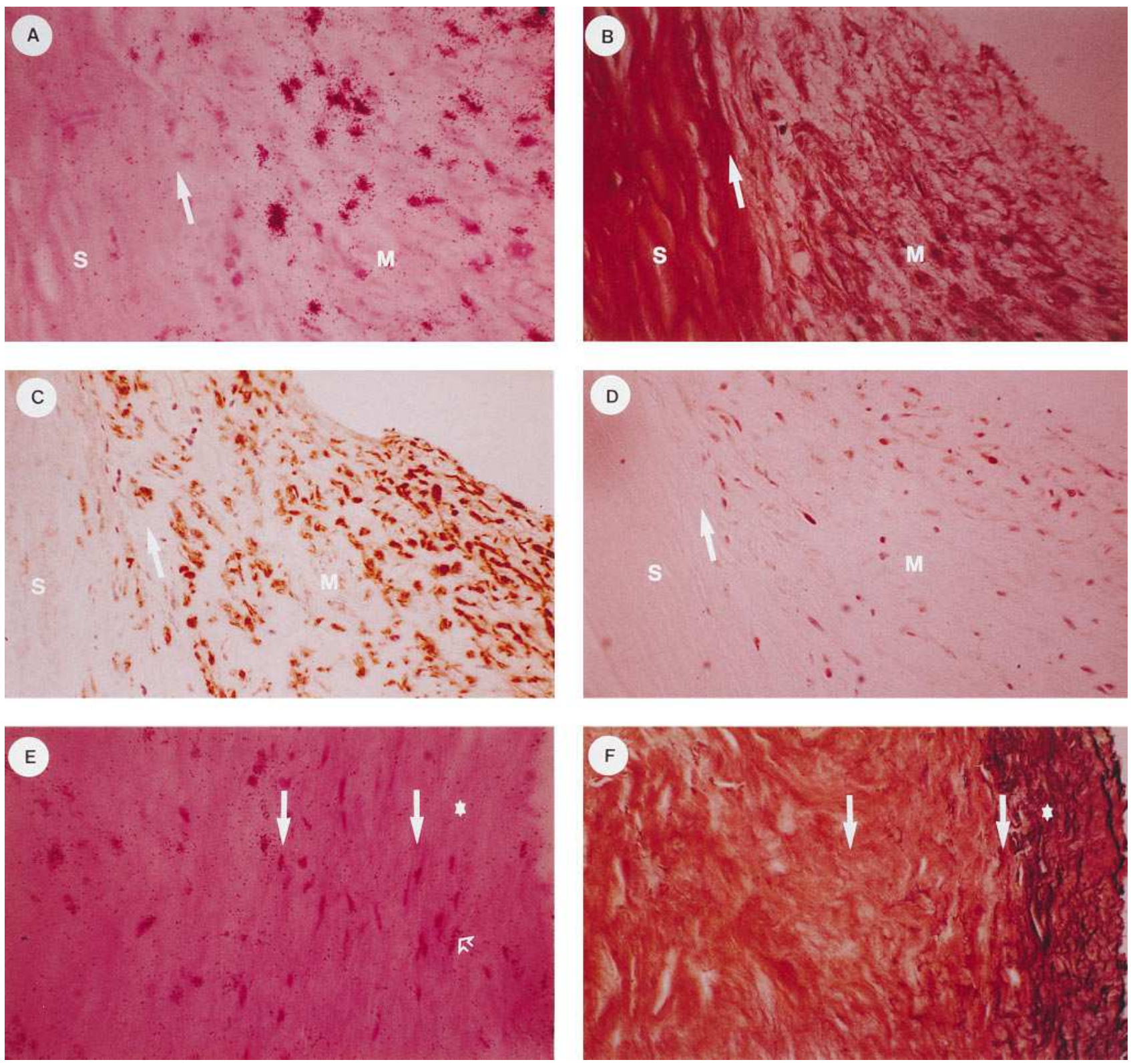

Figure 8. Expression of $\mathrm{H} 19$ in the human coronary atherosclerotic plaque. (A) Paraffin-embedded human coronary atherosclerotic plaques were hybridized with ${ }^{35}$ S-labeled antisense oligonucleotide probe against human H19 RNA. Specific distribution of silver grains was seen in many of the cells within the myxomatous region $(M)$ but not in the sclerotic region $(S)$. Serial sections were also stained by Van Gieson-elastin $(B)$, immunostained with $\alpha$-smooth muscle actin antibody $(C)$, and PCNA antibody $(D)$. The junction between the sclerotic and the myxomatous region is delineated by an arrow. $E$ and $F$ illustrate an intimal region that contained aligned, spindle-shaped cells and elastic fibers. These morphological features suggest that this is a segment of coronary intima near the internal elastic lamina, representing the most mature and stable part of the intimal thickening. Many H19-positive cells are shown in $E$ and the open arrow denotes a rare H19-positive cell within the aligned cell region. Van Gieson-elastin staining $(F)$ demonstrates the presence of elastin (black) in the region denoted by the asterisk. The double arrows indicate a transitional area containing loose elastic fibers and aligned spindle-shaped cells.

sin heavy chain expression. Furthermore, our results suggest that this developmental transition in the smooth muscle, unlike that observed for skeletal muscle, is not coupled to cell cycle growth arrest.

Reexpression of $\mathrm{H} 19$ in the adult atherosclerotic plaque may reflect recapitulation of earlier developmental events. Research interests in the developmental maturation of SMCs arise from the morphological and biochemical similarities that have been noted between developmentally immature SMCs and lesion-derived SMCs in the adult animal (20-27). These similarities have led to the suggestion that in atherosclerosis and in hypertension SMCs may recapitulate certain aspects of earlier developmental events $(21,35)$. We have found that, although not normally expressed by adult SMCs, H19 is reexpressed by modified cells of the atherosclerotic plaque. Given that $\mathrm{H} 19$ is also reexpressed by rat intimal SMCs after blood vessel injury (36), it is possible that the actin-positive, stellateshaped H19-expressing cells are modified SMCs. However, we also found that H19 was expressed by endothelial cells early during prenatal development and it is possible that some of the 
H19-positive cells in the atherosclerotic plaque are of endothelial origin. Irrespective of the origin of the H19-positive plaque cells, our data suggest that these cells may undergo developmental recapitulation events.

$H 19$ regulation by the insulin family of growth factors. Elegant studies have previously delineated the $5^{\prime}$ proximal promoter and 3 '-flanking enhancer elements necessary for the expression of $\mathrm{H} 19$ in liver cells (37). Based on the similar pattern of expression of IGF-II and H19 during embryogenesis and fetal development $(17,38)$, their adjacent physical chromosomal location (39), and their opposed imprinting pattern $(4,40)$, it was proposed that these genes may use a set of common regulatory elements including the 3 '-flanking endoderm-specific enhancers defined for H19 (41). Recent transgenic studies revealed that deletion of the maternal $\mathrm{H} 19$ gene resulted in animals that expressed a higher level of IGF-II mRNA and are $27 \%$ heavier (42). This increase was restricted to heterozygotes with the maternal deletion and was attributed to a gain of function of the IGF-II gene. These results support the imprinting model that H19 and IGF-II use a set of common regulatory elements with normal preferential transcription of the maternal-derived H19 gene, possibly due to a stronger promoter or proximity to the enhancer elements and methylationinduced inactivation of the paternal-derived H19 gene and consequent transcription of the paternal IGF-II gene $(41,42)$. In this model, the utilization of similar cis and trans regulatory elements presumably accounts for the similar pattern of H19 and IGF-II expression during development. However, the cis elements that regulate expression of the H19 gene in mesoderm-derived tissues have not been delineated and the transcriptional factors responsible for developmentally regulated H19 expression remain unknown. We have demonstrated previously that $\mathrm{H} 19$ and IGF-II expression patterns are similar in the developing aorta and that fetal specific expression of these genes is maintained in vitro (9). Using cultured fetal SMCs, we have now provided evidence for the presence of both positive and negative $\mathrm{H} 19$ regulatory factors. This culture system will be useful for further delineating the regulatory network responsible for $\mathrm{H} 19$ expression in mesoderm-derived cells. The identification of the insulin family of growth factors as positive regulatory factors for H19 expression is interesting from the perspective of cardiovascular diseases since elevated IGF-I expression can be detected in both the balloon-injured rat aorta and in the human atherosclerotic plaque $(43,44)$. It is possible that during embryonic and fetal development locally expressed IGFs could be a permissive factor for H19 expression and partially account for their similar pattern of expression during development.

\section{Acknowledgments}

This manuscript is dedicated to the memory of Dr. R.A. Majack.

This work was supported in part by a grant from the National Institutes of Health (HL-37510 to G. Liau). Additional support was provided by a Grant-in-Aid from the American Heart Association with funds contributed in part by the AHA, Maryland Affiliate.

\section{References}

1. Brunkow, M.E., and S.M. Tilghman. 1991. Ectopic expression of the H19 gene in mice causes prenatal lethality. Genes \& Dev. 5:1092-1101.

2. Hao, Y., T. Crenshaw, T. Moulton, E. Newcomb, and B. Tycko. 1993. Tu- mour-suppressor activity of H19 RNA. Nature (Lond.). 365:764-767.

3. Steenman, M.J.C., S. Rainier, C.J. Dobry, P. Grundy, I.L. Horon, and A.P. Feinberg. 1994. Loss of imprinting of IGF2 is linked to reduced expression and abnormal methylation of H19 in Wilms' tumour. Nat. Genet. 7:433-438.

4. Bartolomei, M.S., S. Zemel, and S.M. Tilghman. 1991. Parental imprinting of the mouse H19 gene. Nature (Lond.). 351:153-155.

5. Zhang, Y., and B. Tycko. 1992. Monoallelic expression of the human H19 gene. Nat. Genet. 1:40-44.

6. Tycko, B. 1994. Genomic imprinting: mechanism and role in human pathology. Am. J. Pathol. 144:431-442.

7. Pachnis, V., C.I. Brannan, and S.M. Tilghman. 1988. The structure and expression of a novel gene activated in early mouse embryogenesis. EMBO (Eur. Mol. Biol. Organ.) J. 7:673-681.

8. Brannan, C.I., E.C. Dees, R.S. Ingram, and S.M. Tilghman. 1990. The product of the H19 gene may function as an RNA. Mol. Cell. Biol. 10:28-36.

9. Han, D.K.M., and G. Liau. 1992. Identification and characterization of developmentally regulated genes in vascular smooth muscle cells. Circ. Res. 71: 711-719.

10. Jacks, T., and H.E. Varmus. 1985. Expression of the Rous sarcoma virus pol gene by ribosomal frameshifting. Science (Wash. DC). 230:1237-1242.

11. Powell, L.M., S.C. Wallis, R.J. Pease, Y.H. Edwards, T.J. Knott, and J. Scott. 1987. A novel form of tissue-specific RNA processing produces apolipoprotein-B48 in intestine. Cell. 50:831-840.

12. Nakamura, H. 1988. Electron microscopic study of the prenatal development of thoracic aorta in the rat. Am. J. Anat. 181:406-418.

13. Karrer, H.E. 1960. Electron microscopic study of developing chick aorta. J. Ultrastruc. Res. 4:420-454.

14. Liau, G., and D.K.M. Han. 1995. Smooth muscle gene expression during developmental maturation. In The Vascular Smooth Muscle Cell. S.M. Schwartz and R. Mecham, editors. Academic Press. 141-161.

15. Young, W.S.I. 1991. In situ hybridization and Northern analyses of the expression of protein kinase $\mathrm{C}$ genes using oligodeoxyribonucleotide probes. Focus (Idaho). 13:46-49.

16. Liau, G., and L.M. Chan. 1989. Regulation of extracellular matrix RNA levels in cultured smooth muscle cells: relationship to cellular quiescence. $J$. Biol. Chem. 264:10315-10320.

17. Poirier, F., C.-T.J. Chan, P.M. Timmons, E.J. Robertson, and M.J. Evans. 1991. The murine H19 gene is activated during embryonic stem cell differentiation in vitro and at the time of implantation in the developing embryo. Development (Camb.). 113:1105-1114.

18. Lustig, O., I. Ariel, J. Ilan, E. Lev-Lehman, N. De-Groot, and A. Hochberg. 1994. Expression of the imprinted gene H19 in the human fetus. Mol. Reprod. Dev. 38:239-246.

19. Davis, R.L., H. Weintraub, and A.B. Lassar. 1987. Expression of a single transfected cDNA converts fibroblasts to myoblasts. Cell. 51:987-1000.

20. Gabbiani, G., O. Kocher, W.S. Bloom, J. Vanderkerckhove, and K. Weber. 1984. Actin expression in smooth muscle cells of rat aortic intimal thickening, human atheromatous plaque, and cultured rat aortic media. J. Clin. Invest. 73:148-152.

21. Kocher, O., O. Skalli, D. Cerutti, and G. Gabbiani. 1985. Cytoskeletal features of rat aortic cells during development. An electron microscopic, immunocytological, and biochemical study. Circ. Res. 56:829-838.

22. Glukhova, M.A., M.G. Frid, and V.E. Koteliansky. 1990. Developmental changes in expression of contractile and cytoskeletal proteins in human aortic smooth muscle. J. Biol. Chem. 265:13042-13046.

23. Kuro-O, M., R. Nagai, K. Nakahara, H. Katoh, R. Tsai, H. Tsuchimochi, Y. Yazaki, A. Ohkubo, and F. Takaku. 1991. cDNA cloning of a myosin heavy chain isoform in embryonic smooth muscle and its expression during vascular development and in arteriosclerosis. J. Biol. Chem. 266:3768-3773.

24. Kuro-O, M., R. Nagai, H. Tsuchimochi, H. Katoh, Y. Yazaki, A. Ohkubo, and F. Takaku. 1989. Developmentally regulated expression of vascular smooth muscle myosin heavy chain isoforms. J. Biol. Chem. 264:18272-18275.

25. Majesky, M.W., C.M. Giachelli, M.A. Reidy, and S.M. Schwartz. 1992. Rat carotid neointimal smooth muscle cells reexpress a developmentally regulated mRNA phenotype during repair of artery injury. Circ. Res. 71:759-768.

26. Aikawa, M., P.N. Sivam, M. Kuro-O, K. Kimura, K. Nakahara, S. Takewaki, M. Ueda, H. Yamaguchi, Y. Yazaki, M. Periasamy, and R. Nagai. 1993. Human smooth muscle myosin heavy chain isoforms as molecular markers for vascular development and atherosclerosis. Circ. Res. 72:1000-1012.

27. Sartore, S., M. Scatena, A. Chiaregato, E. Eaggin, L. Giuriato, and P. Pauletto. 1994. Myosin isoform expression in smooth muscle cells during physiological and pathological vascular remodeling. J. Vasc. Res. 31:61-81.

28. Pachnis, V., A. Belayew, and S.M. Tilghman. 1984. Locus unlinked to alpha-feto-protein under the control of raf and rif genes. Proc. Natl. Acad. Sci. USA. 81:5523-5527.

29. Parker, S.B., G. Eichele, P. Zhang, A. Rawls, A.T. Sands, A. Bradley, E.N. Olson, J.W. Harper, and S.J. Elledge. 1995. p53-independent expression of p21 ${ }^{\text {Cip } 1}$ in muscle and other terminally differentiating cells. Science (Wash. DC) 267:1024-1027.

30. Halevy, O., B.G. Novitch, D.B. Spicer, S.X. Skapek, J. Rhee, G.J. Hannon, D. Beach, and A.B. Lassar. 1995. Correlation of terminal cell cycle arrest of skeletal muscle with induction of $\mathrm{p} 21$ by myoD. Science (Wash. DC). 267: 
1018-1021.

31. Davis, E.C. 1993. Smooth muscle cell to elastic lamina connections in developing mouse aorta. Lab. Invest. 68:89-99.

32. Cook, C.K., M.C.M. Weiser, P.E. Schwartz, C.L. Jones, and R.A. Majack. 1994. Developmentally timed expression of an embryonic growth phenotype in vascular smooth muscle cells. Circ. Res. 74:189-196.

33. Miano, J.M., P. Cserjesi, K.L. Ligon, M. Periasamy, and E.N. Olson. 1994. Smooth muscle myosin heavy chain exclusively marks the smooth muscle lineage during mouse embryogenesis. Circ. Res. 75:803-812.

34. Giuriato, L., M. Scatena, A. Chiavegato, M. Tonello, G. Scannapieco, P. Pauletto, and S. Sartore. 1992. Non-muscle myosin isoforms and cell heterogeneity in developing rabbit vascular smooth muscle. J. Cell Sci. 101:233-246.

35. Schwartz, S.M., G.R. Campbell, and J.H. Campbell. 1986. Replication of smooth muscle cells in vascular disease. Circ. Res. 58:427-444.

36. Kim, D., L. Zhang, V.J. Dzau, and R.E. Pratt. 1994. H19, a developmentally regulated gene, is reexpressed in rat vascular smooth muscle cells after injury. J. Clin. Invest. 93:355-360.

37. Yoo-Warren, H., V. Pachnis, R.S. Ingram, and S.M. Tilghman. 1988. Two regulating domains flank the mouse H19 gene. Mol. Cell. Biol. 8:47074715 .

38. Lee, J., J. Pintar, and A. Efstratiadis. 1990. Pattern of the insulin-like growth factor II gene expression during early mouse embryogenesis. Development (Camb.). 110:151-159.

39. Zemel, S., M.S. Bartolomei, and S.M. Tilghman. 1992. Physical linkage of two mammalian imprinted genes, H19 and insulin-like growth factor 2. Nat. Genet. 2:61-65.

40. DeChiara, T.M., E.J. Robertson, and A. Efstratiadis. 1991. Parental imprinting of the mouse insulin-like growth factor II gene. Cell. 64:849-859.

41. Bartolomei, M., A.L. Webber, M.E. Brunkow, and S.M. Tilghman. 1993. Epigenetic mechanisms underlying the imprinting of the mouse H19 gene. Genes \& Dev. 7:1663-1673.

42. Leighton, P.A., R.S. Ingram, J. Eggenschwiler, A. Efstratiadis, and S.M. Tilghman. 1995. Disruption of imprinting caused by deletion of the H19 gene region in mice. Nature (Lond.). 375:34-39.

43. Cercek, B., M.C. Fishbein, J.S. Forrester, R.H. Helfant, and J.A. Fagin. 1990. Induction of insulin-like growth factor I messenger RNA in rat aorta after balloon denudation. Circ. Res. 66:1755-1760.

44. Grant, M.B., T.J. Wargovich, E.A. Ellis, S. Caballero, M. Mansour, and C.J. Pepine. 1994. Localization of insulin-like growth factor I and inhibition of coronary smooth muscle cell growth by somatostatin analogues in human coronary smooth muscle cells. Circulation. 89:1511-1517. 